\title{
ARTICLE
}

Received 3 Jun 2015 | Accepted 23 Jun 2015 | Published 10 Aug 2015

\section{A scalable and operationally simple radical trifluoromethylation}

Joel W. Beatty ${ }^{1}$, James J. Douglas ${ }^{1,2}$, Kevin P. Cole ${ }^{2} \&$ Corey R.J. Stephenson ${ }^{1}$

The large number of reagents that have been developed for the synthesis of trifluoromethylated compounds is a testament to the importance of the $\mathrm{CF}_{3}$ group as well as the associated synthetic challenge. Current state-of-the-art reagents for appending the $\mathrm{CF}_{3}$ functionality directly are highly effective; however, their use on preparative scale has minimal precedent because they require multistep synthesis for their preparation, and/or are prohibitively expensive for large-scale application. For a scalable trifluoromethylation methodology, trifluoroacetic acid and its anhydride represent an attractive solution in terms of cost and availability; however, because of the exceedingly high oxidation potential of trifluoroacetate, previous endeavours to use this material as a $\mathrm{CF}_{3}$ source have required the use of highly forcing conditions. Here we report a strategy for the use of trifluoroacetic anhydride for a scalable and operationally simple trifluoromethylation reaction using pyridine $\mathrm{N}$-oxide and photoredox catalysis to affect a facile decarboxylation to the $\mathrm{CF}_{3}$ radical.

\footnotetext{
${ }^{1}$ Department of Chemistry, University of Michigan, Ann Arbor, Michigan 48109, USA. ${ }^{2}$ Small Molecule Design and Development, Lilly Research Laboratories, Eli Lilly and Company, Indianapolis, Indiana 46285, USA. Correspondence and requests for materials should be addressed to C.R.J.S. (email: crjsteph@umich.edu).
} 
$\mathrm{T}$ he incorporation of fluorine into drug molecules can dramatically improve metabolic stability and other pharmacokinetic properties ${ }^{1}$, a phenomenon reflected by the presence of fluorine in a large proportion of recent drug candidates $^{2}$. Technologies for introducing fluorine and the trifluoromethyl $\left(\mathrm{CF}_{3}\right)$ group have become increasingly available to medicinal chemists for the synthesis and development of lead compounds ${ }^{3,4}$. Currently, a number of effective methodologies utilizing radical ${ }^{3,5-9}$, nucleophilic ${ }^{3,10-14}$ and electrophilic $3,15,16 \mathrm{CF}_{3}$ sources are available for arene and heteroarene trifluoromethylation. The development of requisite methodologies for trifluoromethylation on preparative scale has become an increasingly important, yet challenging priority. Compounding this issue, many reagents most commonly used for laboratory-scale trifluoromethylation are prohibitively expensive and/or unobtainable in the quantities required for scale-up (for a cost comparison, see Supplementary Note 1$)^{17}$. As a consequence, advancements in scalable, inexpensive and operationally simple protocols for fluorine incorporation are of the utmost importance for modern pharmaceutical ${ }^{2}$, agrochemical ${ }^{18}$ and specialty chemical production ${ }^{19}$.

To this end, we report a strategy for the use of trifluoroacetic anhydride for a scalable and operationally simple trifluoromethylation reaction using pyridine $\mathrm{N}$-oxide and photoredox catalysis to effect decarboxylation to the $\mathrm{CF}_{3}$ radical. The reaction proceeds on a range of vinyl, aryl and heteroaryl substrates and has been demonstrated on a significant scale in both batch $(100 \mathrm{~g})$ and flow $(20 \mathrm{~g})$.

\section{Results}

Reaction design. Trifluoroacetic acid (TFA) and its anhydride (TFAA) represent attractive sources of $\mathrm{CF}_{3}$ because of their ready availability and inexpensive nature (TFAA $\$ 35$ per $\mathrm{kg}$ at $1,000 \mathrm{~kg}$ ) but have seen minimal application towards this end. This dearth of methods is a direct result of the challenge associated with the decarboxylation of TFA (Fig. 1a)-a process that occurs in a polar manner only at high temperatures $\left(>140^{\circ} \mathrm{C}\right.$ for copper trifluoroacetate $)^{20,21}$. Alternative methods avoiding these high temperatures employ strongly oxidizing conditions (stoichiometric silver ${ }^{22}, \mathrm{XeF}_{2}$ (ref. 23) or peroxide ${ }^{24}$ ) to access the carboxylate radical, which then extrudes $\mathrm{CO}_{2}$ to produce the $\mathrm{CF}_{3}$ radical $^{25}$. Because of the exceedingly high oxidation potential of the TFA anion $\left(\mathrm{F}_{3} \mathrm{CCO}_{2} \mathrm{Na} E_{1 / 2}{ }^{\text {ox }}>+2.4 \mathrm{~V}\right.$ versus SCE (saturated calomel electrode) $)^{26}$, direct electrochemical methods are limited in scope, as these forcing potentials are strong enough to oxidize most organic solvents.

To address this challenge, we envisioned that a mild decarboxylation of TFAA could be accomplished through appending a sacrificial redox auxiliary to alter the requisite electrochemical potentials (Fig. 1b) ${ }^{27}$. As part of the implementation of this design strategy, we took into account aspects of Oda and Okadas' studies on the use of $N$-(acyloxy)phthalimides to facilitate decarboxylation ${ }^{28}$, as well as insights from Barton on the use of thiohydroxamic acid derivatives as photocleavable auxiliarie ${ }^{29}$. In this regard, the use of an electron-rich auxiliary would enable the oxidation of the TFAA adduct at less-forcing potentials; however, because of electronic matching effects, the resultant electrophilic $\mathrm{CF}_{3}$ radical would be highly likely to recombine with the cleaved auxiliary ${ }^{30}$. The alternative reduction of an electron-poor auxiliary presents a solution to this problem, as the use of an electron-poor reagent would fail to out-compete more electron-rich substrates for $\mathrm{CF}_{3}$ radical sequestration.

We identified pyridine $\mathrm{N}$-oxide as the reagent of choice for the formation of a reducible TFAA adduct (Fig. 1b). The reagent combination is effective in equal stoichiometry with respect to the substrate, and is sufficiently inexpensive for large-scale implementation (pyridine $\mathrm{N}$-oxide $\$ 40-\$ 70$ per $\mathrm{kg}$ at $1,000 \mathrm{~kg}$ ). Furthermore, following cleavage of the weak $\mathrm{N}-\mathrm{O}$ bond and $\mathrm{CO}_{2}$ extrusion, the generation of pyridine as a byproduct is a highly beneficial design feature, preventing the need for exogenous base

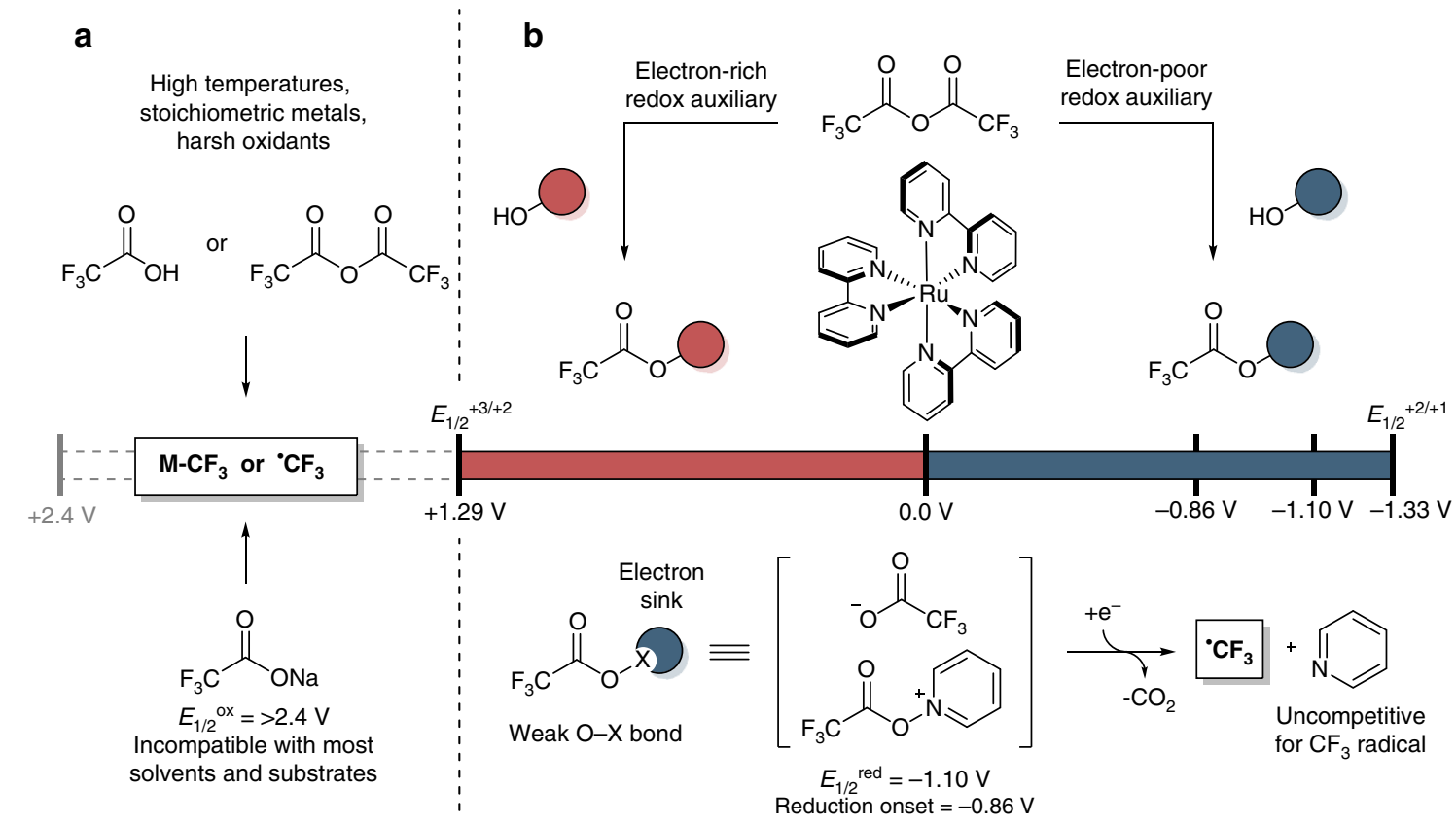

Figure 1 | Design principles for a mild photochemical decarboxylation of trifluoroacetate. (a) TFA and TFAA are desirable $\mathrm{CF}_{3}$ sources from the perspective of availability and cost, but have traditionally proven challenging to utilize. (b) Strategic electrochemical tuning using the sacrificial redox auxiliary pyridine $\mathrm{N}$-oxide allows for reductive decarboxylation within the electrochemical window of tris(bipyridine)ruthenium(II). The reagent undergoes irreversible reduction (determined with differential pulse voltammetry, $E_{1 / 2}{ }^{\text {red }}=-1.10 \mathrm{~V}$ versus SCE in MeCN, Supplementary Figs 1 and 2 ) with onset reduction observable at $-0.86 \mathrm{~V}$ versus SCE. 
and avoiding competitive reagent functionalization. The adduct exhibits reduction at mild potentials $\left(E_{1 / 2}{ }^{\text {red }}=-1.10 \mathrm{~V}\right.$ versus SCE) with an observable reduction onset at $-0.86 \mathrm{~V}$ versus SCE. The use of a photoactive redox catalyst such as tris(bipyridine)ruthenium(II) chloride ${ }^{31}\left(\mathrm{Ru}(\mathrm{bpy})_{3} \mathrm{Cl}_{2}\right)$ was seen as ideal, as its broad electrochemical window encompasses the reduction potential of the $N$-oxide/TFAA adduct (Fig. 1b), and should provide feasible scalability through redox-neutral catalytic operation $^{32}$. Stern-Volmer quenching studies suggest that the adduct is effective in oxidatively quenching the catalyst's excited state (see Supplementary Fig. 3); however, it should be noted that the measured onset reduction of the reagent is more negative than the calculated half wave reduction potential of the $\mathrm{Ru}(\mathrm{bpy})_{3}^{2+*}$ excited state $\left(E_{1 / 2}{ }^{\star \mathrm{II} / \mathrm{III}}=-0.81 \mathrm{~V}\right)^{32}$.

Trifluoromethylation of vinyl, aryl and heteroaryl substrates. Trifluoromethylation reactions were performed in acetonitrile, with 1-2 equivalents of pyridine $N$-oxide providing generally optimal results (Fig. 2, for optimization details see Supplementary Table 1). Importantly, the reaction was found to be tolerant of air and adventitious moisture, resulting in a practical reaction set-up without the need for dry solvent, pre-dried reagents (pyridine
$\mathrm{N}$-oxide is hygroscopic), or degassing of the reaction mixture. Arenes containing both electron-donating and mildly electron-withdrawing groups could be trifluoromethylated in moderate yields (Fig. 2a, 1-3), and benzene could be trifluoromethylated in $45 \%$ yield (4). A variety of heterocycles could also be functionalized (5-10), and aryl bromides were found to be well tolerated by the reaction conditions (Fig. 2b). In addition, atom transfer reactivity was accessible on a number of substrates (Fig. 2c) with effective control for hydrolysis (14), elimination (15) and cyclization (16) of the $\mathrm{CF}_{3}$ addition products.

Free $\mathrm{NH}$ and $\mathrm{OH}$ groups are unsurprisingly acylated in the presence of TFAA, resulting in a decrease in substrate electron density and corresponding reactivity. For example, $N$-Boc-aniline is readily acylated, and the resulting $N$-acyl carbamate is not trifluoromethylated under the reaction conditions. In addition, certain electron-rich substrates undergo Friedel-Crafts reactivity in the presence of TFAA, including 5-(4-bromophenyl)oxazole (precursor to 10, partial acylation), and $N$-phenyl pyrrole. In the case of $N$-phenyl pyrrole, the use of an additional equivalent of TFAA results in formation of 7 in one pot. Under optimized conditions, as shown in Fig. 2, minimal quantities of trifluoromethylated pyridine derivatives were observed $(\leq 5 \%)$; however,
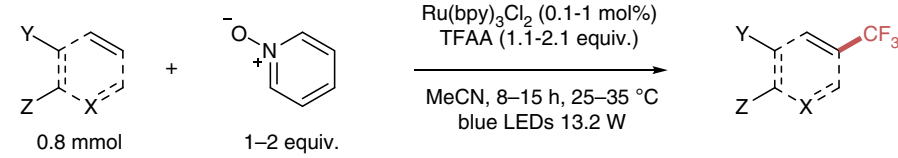

a<smiles>COc1ccc(OC)c(C(F)(F)F)c1</smiles><smiles>CC(=O)c1cccc(C)c1C(=O)O</smiles><smiles>COC(=O)c1ccc(OC)c(C(F)(F)F)c1</smiles>
(3:2)<smiles>CC(=O)c1cc(C(F)(F)F)c(=O)n([Na])c1</smiles><smiles>O=C(c1ccc(C(F)(F)F)n1-c1ccccc1)C(F)(F)F</smiles><smiles>O=C(c1ccccc1)n1c(C(F)(F)F)cc2ccccc21</smiles>
8: $25 \%$<smiles>FC(F)(F)c1ccccc1</smiles>

4: $45 \%$ "ा<smiles>Cc1c(C(F)(F)F)oc2ccccc12</smiles>

9: $37 \%$<smiles>COc1ncnc(OC)c1C(F)(F)F</smiles>
5: $30 \%$<smiles>FC(F)(F)c1n[c]c(-c2ccc(Br)cc2)o1</smiles>

10: $17 \%(1: 1)$

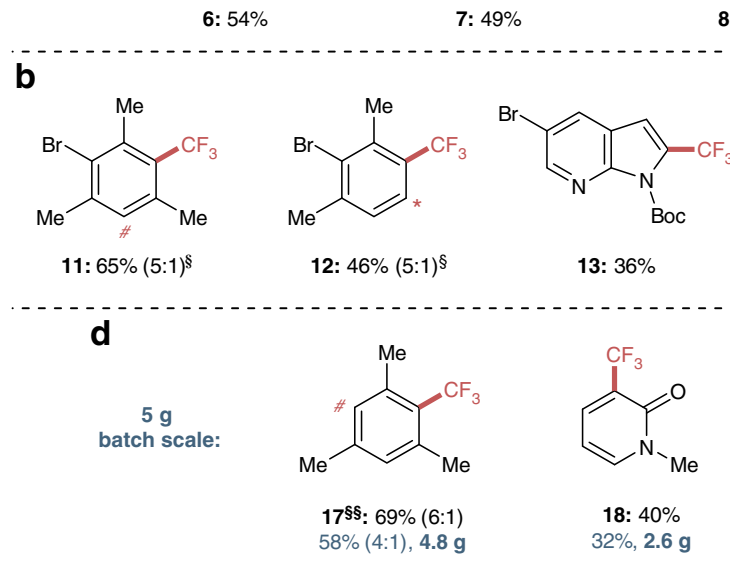<smiles>OC(CC(F)(F)F)c1ccccc1</smiles>

14: $46 \%^{\dagger}$<smiles>N#Cc1ccc(/C=C/C(F)(F)F)cc1</smiles>

15: $56 \%$

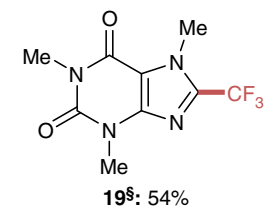

$195: 54 \%$
$58 \%, 3.9 \mathrm{~g}$<smiles>CN1C(=O)C(C)(CC(F)(F)F)c2ccccc21</smiles>

16: $40 \%$

Figure 2 | Scalable radical trifluoromethylation of arenes, heteroarenes and alkenes with trifluoroacetic anhydride. (a) A variety of electron-rich and electron-neutral substrates are amenable to trifluoromethylation. (b) Substrates with functionality for cross-coupling were compatible with the reaction conditions. (c) Radical trifluoromethylation of alkenes. (d) Products 17-20 were obtained from reactions run on $5 \mathrm{~g}$ scale using $0.1 \mathrm{~mol} \% \mathrm{Ru}(\mathrm{bpy})_{3} \mathrm{Cl} \mathrm{L}_{2}$. Isolated yields are indicated below each entry, except in the case of volatile compounds ( ${ }^{19} \mathrm{~F} \mathrm{NMR}$ yields) and represent a single experiment. See

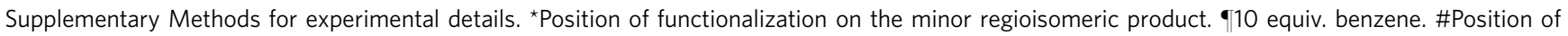
functionalization on the minor doubly functionalized product. $\$ 4$ equiv. of pyridine $\mathrm{N}$-oxide and 8 equiv. of TFAA, $24 \mathrm{~h}$. $\dagger \mathrm{Run}_{\mathrm{n}}$ in $\mathrm{CH}_{2} \mathrm{Cl}{ }_{2}$, stirred with methanol on reaction completion. †Run in $\mathrm{CH}_{2} \mathrm{Cl}_{2}$, stirred with DBU on reaction completion. $\S \S 3$ equiv. of pyridine $\mathrm{N}$-oxide and 3.1 equiv. of TFAA. $\mathrm{Ru}\left(\right.$ bpy) ${ }_{3} \mathrm{Cl}_{2}$, tris(bipyridine)ruthenium(II) chloride; TFAA, trifluoroacetic anhydride; $\mathrm{MeCN}$, acetonitrile; Me, methyl; Boc, tert-butyloxycarbonyl; Ph, phenyl; Ts, para-toluenesulfonyl. 
small amounts of trifluoromethylated byproducts could be observed with increasing equivalents of pyridine $\mathrm{N}$-oxide. While there are many reported methodologies employing the radical addition of $\mathrm{CF}_{3}$ to pyridine derivatives, we observe a high preference for substrate functionalization, validating a critical aspect of our reaction design. Consistent with these observations, electron-poor substrates including pyridines displayed minimal reactivity (see Supplementary Fig. 4). Substrate $\mathrm{C}-\mathrm{H}$ functionalization during the reaction results in the generation of acid, which is inherently buffered by the concomitant formation of free pyridine. This buffering effect also results in a more pronounced difference between the electron density of the substrate and that of pyridinium trifluoroacetate. On reaction completion, these polar products of reagent consumption could be easily removed, either through direct filtration of the reaction mixture or through aqueous workup.

The simplicity of operation and availability of reagents combined to allow us to demonstrate the reaction on preparative laboratory scale. Conducting the reaction on $5 \mathrm{~g}$ of material in commonly available laboratory glassware employing $0.1 \mathrm{~mol} \%$ $\mathrm{Ru}(\text { bpy })_{3} \mathrm{Cl}_{2}$, we observed only a moderate reduction in isolated yield (Fig. 2d, 17-20) realizing our goal of scalability, and demonstrating the potential application of this methodology.

a
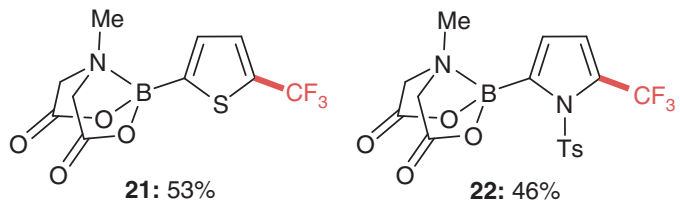

b

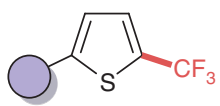

21

$5 \mathrm{~g}$ scale: $39 \%, 2.5 \mathrm{~g}$
5 g scale: $27 \%, 1.7 \mathrm{~g}$

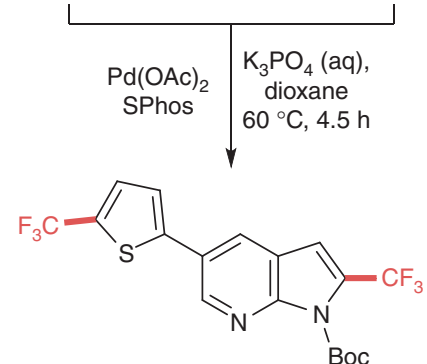

23: $63 \%$

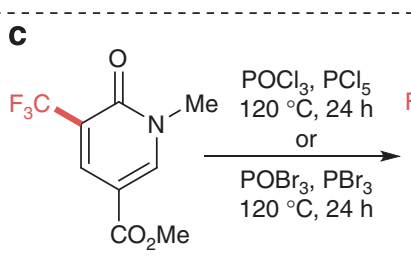

6: $54 \%$

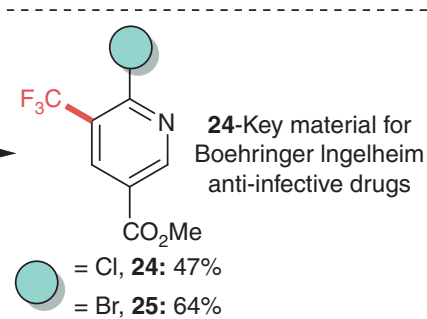

Figure 3 | Synthetic utility of the trifluoromethylation procedure.

(a) Trifluoromethylation of cross-coupling precursors. (b) Trifluoromethylation followed by cross-coupling leads to the production of specialty scaffolds. (c) Synthesis of 3-(trifluoromethyl)pyridine derivatives can be accomplished through pyridone functionalization. Boc, tert-butyloxycarbonyl; SPhos, 2-dicyclohexylphosphino-2', 6'-dimethoxybiphenyl; BMIDA, boronic acid methyliminodiacetic acid ester. Yields represent a single experiment.
Preparative scale reactions on materials containing the appropriate handle to allow further functionalization also proceeded successfully. Methyliminodiacetic acid ester (MIDA) boronates $\mathbf{2 1}$ and $\mathbf{2 2}$ could be readily obtained via the trifluoromethylation conditions, demonstrating the stability of the MIDA functionality to these radical conditions (Fig. 3a). Thiophene 21 was produced on a $5-\mathrm{g}$ scale and cross-coupled with azaindole 13 to provide the highly functionalized doubly trifluoromethylated compound 23 (Fig. 3b). This trifluoromethylation/cross-coupling strategy represents an attractive tool to rapidly access a wide range of $\mathrm{CF}_{3}$-containing scaffolds, with potential application to the construction of compound libraries used in drug discovery. This type of approach is a complementary strategy to late-stage trifluoromethylation, by which functional-group diversity is generated from a single advanced intermediate ${ }^{5}$.

Application to the synthesis of $\mathrm{CF}_{3}$ pyridines. While the methodology is not currently applicable to direct the formation of medicinally relevant pyridine substrates, 2-halo-3-trifluoromethylated pyridine motifs can be accessed via further transformation of $\mathrm{N}$-methyl-2-pyridone analogues such as $\mathbf{6}$ (Fig. 3c). 2-Halo-3-trifluoromethylated pyridines are useful building blocks that can serve as versatile precursors to drug-like compounds; for example, pyridine $\mathbf{2 4}$ represents a key starting material for anti-infective drugs currently in development by Boehringer Inglehiem ${ }^{17}$. The current route to kilogram quantities of 24 was developed with an emphasis on cost, limiting reagent choice (see Supplementary Note 1), as 'the large-scale availability of $\mathrm{CF}_{3} \mathrm{SiMe}_{3}$ and higher alkyl variants is still limited and their cost can be prohibitive for use in commercial pharmaceutical manufacture' ${ }^{\prime 7}$. We viewed this substrate as an ideal test of the strategic use of our trifluoromethylation procedure. Accordingly, $\mathrm{N}$-methyl pyridone 6 was synthesized in 54\% yield from the corresponding pyridone then converted to pyridine $\mathbf{2 4}$ (47\% yield
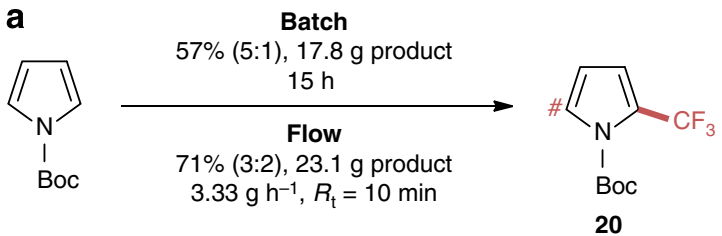

b

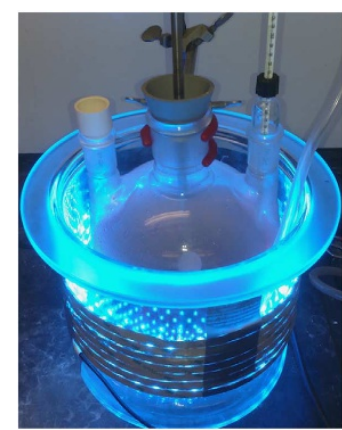

Batch

$100 \mathrm{~g}$ scale 62 h, 35\% (13:1)

Total reagent cost $<\$ 150$

Figure 4 | Scalable trifluoromethylation of $\mathbf{N}$-Boc-pyrrole in batch and flow. (a) An 18.3-g reaction in batch provides $17.8 \mathrm{~g}$ of product (57\%) in $15 \mathrm{~h}$. Improved yields were obtained when the reaction was run at a steady state in flow, with a $71 \%$ yield of isolated material from $20 \mathrm{~g}$ of starting material. (b) The reaction can be run on $100 \mathrm{~g}$ scale for $<\$ 150$ total reagent and catalyst cost calculated using academic vendor pricing. \#Position of functionalization on the minor doubly functionalized product. Yields represent a single experiment. Boc, tert-butyloxycarbonyl. 
unoptimized) to provide the desired compound and demonstrate an alternative synthesis utilizing TFAA.

Reactions at large scale and in flow. Owing to the minimal cost of the reagent and low catalyst loadings, we began to assess the viability of this reaction on process scale (Fig. 4). A reaction conducted using $18 \mathrm{~g}$ of $\mathrm{N}$-Boc-pyrrole provided a comparable yield to that obtained on small scale (17.8 g 57\%). Furthermore, a promising yield of $35 \%$ was obtained on $100 \mathrm{~g}$ of material; the reaction time was notably longer (62 versus $15 \mathrm{~h}$ ), a feature that can be attributed to a reduction in the relative light intensity in the larger vessel as we chose not to fully optimize the light source at this time (see Supplementary Methods). These initial results indicate that the method is potentially applicable to large-scale batch production; however, another attractive option for scale up involves the use of continuous processing. The benefits from conducting photochemical reactions in flow have been previously demonstrated ${ }^{33,34}$, and predominantly originate from more efficient light irradiation of the reaction solution. A preliminary study found improved results $(23.1 \mathrm{~g} 71 \%)$ for a 20 -g reaction performed in flow with a residence time of $10 \mathrm{~min}(10 \mathrm{ml}$ reactor volume), demonstrating the viability of this procedure in the context of continuous processing (Supplementary Fig. 5). Efforts towards further batch scale up combined with optimization of the continuous flow conditions are ongoing and will be reported in due course.

\section{Discussion}

The direct trifluoromethylation of arenes and heteroarenes circumvents more traditional multistep procedures for $\mathrm{CF}_{3}$ arene production, most notably the radical chlorination of aryl methyl groups followed by high-pressure treatment in hydrofluoric $\operatorname{acid}^{35}$. This current industrial standard has been demonstrated to be highly effective; however, alternative functional-group tolerant procedures for direct trifluoromethylation remain an important priority. In this regard, further work to utilize inexpensive and atom-economical $\mathrm{CF}_{3}$ sources such as $\mathrm{HCF}_{3}$ or TFA should be prioritized. The challenge of utilizing TFAA as a $\mathrm{CF}_{3}$ source is reflected by moderate yields for the reported transformation; nevertheless, this work represents a significant breakthrough that will allow for further understanding of this reactivity, with the aim of developing a cost-effective large-scale route to specialty trifluoromethylated chemicals. Finally, while trifluoromethylation has demonstrated its synthetic value in the pharmaceutical, agrochemical and fine chemical industries, radical perfluoroalkylation has found widespread use in the synthesis of specialty materials and in fluorous tagging ${ }^{36}$. Owing to the availability of various perfluoroalkyl anhydrides, we believe that our method may find use in this regard, or furthermore as a general means of accessing radical species from carboxylic acids that are challenging to oxidize via traditional means.

\footnotetext{
Methods

General trifluoromethylation procedure. To a 2-dram vial equipped with a stir bar was added pyridine $N$-oxide ( $76 \mathrm{mg}, 0.80 \mathrm{mmol}, 1.0$ equiv), $\mathrm{Ru}(\mathrm{bpy})_{3} \mathrm{Cl}_{2} \bullet 6 \mathrm{H}_{2} \mathrm{O}$ $(6.0 \mathrm{mg}, 1.0 \mathrm{~mol} \%)$ and substrate $(0.80 \mathrm{mmol})$. The combined materials were then dissolved in $\mathrm{MeCN}(2.0 \mathrm{ml})$ and stirred to form a homogeneous solution. Trifluoroacetic anhydride $(120 \mu \mathrm{l}, 180 \mathrm{mg}, 0.88 \mathrm{mmol}, 1.1$ equiv) was then added to the resulting solution. The vial was equipped with a screw-on cap with septum, and a 25-gauge needle was placed through the septum for the duration of the reaction. Three $4.4 \mathrm{~W}$ LED light strips (positioned $2.5 \mathrm{~cm}$ away) were turned on and the reaction was allowed to run for $12-15 \mathrm{~h}$ before the light source was removed. Workup was performed by diluting the reaction with $\mathrm{CH}_{2} \mathrm{Cl}_{2}$ and washing with $1 \mathrm{~N}$ $\mathrm{HCl}$, followed by saturated $\mathrm{NaHCO}_{3}$ and then brine. The organic layer was dried over sodium sulfate before filtering and concentrating at $40^{\circ} \mathrm{C}$ under reduced pressure. For NMR analysis of the compounds in this article, see Supplementary Figs 6-46.
}

\section{References}

1. Müller, K., Faeh, C. \& Diedrich, F. Fluorine in pharmaceuticals: looking beyond intuition. Science 317, 1881-1886 (2007).

2. Hagmann, W. K. The many roles for fluorine in medicinal chemistry. J. Med. Chem. 51, 4359-4369 (2008)

3. Alonso, C., De Marigorta, E. M., Rubiales, G. \& Palacios, F. Carbon trifluoromethylation reactions of hydrocarbon derivatives and heteroarenes. Chem. Rev. 115, 1847-1935 (2015).

4. Liang, T., Neumann, C. N. \& Ritter, T. Introduction of fluorine and fluorinecontaining functional groups. Angew. Chem. Int. Ed. 52, 8214-8264 (2013).

5. Nagib, D. A. \& MacMillan, D. W. C. Trifluoromethylation of arenes and heteroarenes by means of photoredox catalysis. Nature 480, 224-227 (2011).

6. Fujiwara, Y. et al. Practical and innate carbon-hydrogen functionalization of heterocycles. Nature 492, 95-99 (2012).

7. Ji, Y. et al. Innate C-H trifluoromethylation of heterocycles. Proc. Natl Acad. Sci. USA 108, 14411-14415 (2011).

8. O'Brien, A. G. et al. Radical C-H functionalization of heteroarenes under electrochemical control. Angew. Chem. Int. Ed. 53, 11868-11871 (2014).

9. Iqbal, N., Choi, S., Ko, E. \& Cho, E. J. Trifluoromethylation of heterocycles via visible light photoredox catalysis. Tetrahedron Lett. 53, 2005-2008 (2012).

10. Cho, E. J. et al. The palladium-catalyzed trifluoromethylation of aryl chlorides. Science 328, 1679-1681 (2010).

11. Morimoto, H., Tsubogo, T., Litvinas, N. D. \& Hartwig, J. F. A broadly applicable copper reagent for trifluoromethylations and perfluoroalkylations of aryl iodides and bromides. Angew. Chem. Int. Ed. 50, 3793-3798 (2011).

12. Mazloomi, Z. et al. Continuous process for production of $\mathrm{CuCF}_{3}$ via direct cupration of fluoroform. Org. Process Res. Dev. 18, 1020-1026 (2014).

13. Lishchynskyi, A. et al. Trifluoromethylation of aryl and heteroaryl halides with fluoroform-derived $\mathrm{CuCF}_{3}$ : Scope, limitations, and mechanistic features. J. Org. Chem. 78, 11126-11146 (2013).

14. Liu, X., Xu, C., Wang, M. \& Liu, Q. Trifluoromethyltrimethylsilane: nucleophilic trifluoromethylation and beyond. Chem. Rev. 115, 683-730 (2015).

15. Charpentier, J., Früh, N. \& Togni, A. Electrophilic trifluoromethylation by use of hypervalent iodine reagents. Chem. Rev. 115, 650-682 (2015).

16. Umemoto, T. Electrophilic perfluoroalkylating reagents. Chem. Rev. 96, 1757-1777 (1996).

17. Mulder, J. A. et al. Development of a safe and economical synthesis of methyl 6-chloro-5-(trifluoromethyl)nicotinate: trifluoromethylation on kilogram scale. Org. Process Res. Dev. 17, 940-945 (2013).

18. Jeschke, $\mathrm{P}$. The unique role of fluorine in the design of active ingredients for modern crop protection. ChemBioChem. 5, 570-589 (2004).

19. Kirsch, P. Modern Fluoroorganic Chemistry: Synthesis, Reactivity, Applications (Wiley, 2004).

20. Matsui, K., Tobita, E., Ando, M. \& Kondo, K. A convenient trifluoromethylation of aromatic halides with sodium trifluoroacetate. Chem. Lett. 10, 1719-1720 (1981)

21. Chen, M. \& Buchwald, S. L. Rapid and efficient trifluoromethylation of aromatic and heteroaromatic compounds using potassium trifluoroacetate enabled by a flow system. Angew. Chem. Int. Ed. 52, 11628-11631 (2013).

22. Lai, C. \& Mallouk, T. E. A new approach to the photochemical trifluoromethylation of aromatic compounds. J. Chem. Soc. Chem. Commun. 17, 1359-1361 (1993).

23. Tanabe, Y., Matsuo, N. \& Ohno, N. Direct perfluoroalkylation including trifluoromethylation of aromatics with perfluoro carboxylic acids mediated by xenon difluoride. J. Org. Chem. 53, 4582-4585 (1988).

24. Sawada, H. Fluorinated peroxides. Chem. Rev. 96, 1779-1808 (1996).

25. Studer, A. A "renaissance" in radical trifluoromethylation. Angew. Chem. Int. Ed. 51, 8950-8958 (2010).

26. Depecker, C., Marzouk, H., Trevin, S. \& Devynck, J. Trifluoromethylation of aromatic compounds via Kolbe electrolysis in pure organic solvent. Study on laboratory and pilot scale. New J. Chem. 23, 739-742 (1999).

27. Tyson, E. L., Farney, E. P. \& Yoon, T. P. Photocatalytic [2+2] cycloadditions of enones with cleavable redox auxiliaries. Org. Lett. 14, 1110-1113 (2012).

28. Okada, K. et al. Photosensitized decarboxylative Michael addition through $N$-(acyloxy)phthalimides via an electron-transfer mechanism. J. Am. Chem. Soc. 113, 9401-9402 (1991).

29. Barton, D. H. R., Crich, D. \& Motherwell, W. B. New and improved methods for the radical decarboxylation of acids. J. Chem. Soc. Chem. Commun. 17, 939-941 (1983).

30. Barton, D. H. R., Lacher, B. L. \& Zard, S. Z. The invention of new radical chain reactions. Part XIII. Generation and reactivity of perfluoroalkyl radicals from thiohydroxamic esters. Tetrahedron 42, 2325-2328 (1986).

31. Juris, A. et al. $\mathrm{Ru}(\mathrm{II})$ polypyridine complexes: photophysics, photochemistry, electrochemistry, and chemiluminescence. Coord. Chem. Rev. 84, 85-277 (1988)

32. Prier, C. K., Rankic, D. A. \& MacMillan, D. W. C. Visible light photoredox catalysis with transition metal complexes: applications in organic synthesis. Chem. Rev. 113, 5322-5363 (2013).

33. Hook, B. D. A. et al. A practical flow reactor for continuous organic photochemistry. J. Org. Chem. 70, 7558-7564 (2005). 
34. Garlets, Z. J., Nguyen, J. D. \& Stephenson, C. R. J. The development of visiblelight photoredox catalysis in flow. Isr. J. Chem. 54, 351-360 (2014).

35. Siegemund, G. et al. Fluorine Compounds, Organic; in Ullmann's Encyclopedia of Industrial Chemistry (Wiley, 2002).

36. Luo, Z., Zhang, Q., Oderaotoshi, Y. \& Curran, D. P. A fluorous-tagging strategy for the synthesis and separation of mixtures of organic compounds. Science 291, 1766-1769 (2001).

\section{Acknowledgements}

We thank Lara Cala Alvarez for preliminary experimental contributions. We also thank Vapourtec Ltd for providing an E-series flow photochemical reactor. We acknowledge the financial support for this research from the NIH-NIGMS (R01-GM096129), the Camille Dreyfus Teacher Scholar Award Program, Eli Lilly and Co., the University of Michigan and from a Lilly Innovation Fellowship Award to J.J.D. from Eli Lilly and Co.

\section{Author contributions}

J.W.B. and J.J.D. performed the experiments; J.W.B., J.J.D., K.P.C. and C.R.J.S. designed the experiments and analysed the data. J.W.B., J.J.D., K.P.C. and C.R.J.S. wrote the manuscript.

\section{Additional information}

Supplementary Information accompanies this paper at http://www.nature.com/ naturecommunications

Competing financial interests: The authors declare no competing financial interests.

Reprints and permission information is available online at http://npg.nature.com/ reprintsandpermissions/

How to cite this article: Beatty, J. W. et al. A scalable and operationally simple radical trifluoromethylation. Nat. Commun. 6:7919 doi: 10.1038/ncomms8919 (2015).

\section{(c) (i)}

This work is licensed under a Creative Commons Attribution 4.0 International License. The images or other third party material in this article are included in the article's Creative Commons license, unless indicated otherwise in the credit line; if the material is not included under the Creative Commons license, users will need to obtain permission from the license holder to reproduce the material. To view a copy of this license, visit http://creativecommons.org/licenses/by/4.0/ 